\title{
The Impact of Gender on Anthropometric Measures of Twins
}

\author{
Shayesteh Jahanfar ${ }^{1}$ and Kenneth Lim ${ }^{2}$ \\ ${ }^{1}$ School of Population and Public Health, University of British Columbia, Vancouver, British Columbia, Canada \\ ${ }^{2}$ Division of Maternal Fetal Medicine, Department of Obstetrics \& Gynecology, University of British Columbia, Vancouver, \\ British Columbia, Canada
}

\begin{abstract}
Introduction: Literature suggests that male hormones influence fetal growth in singleton pregnancies. We hypothesized that the same phenomenon is seen in twin gestations. Objectives: (1) to identify the impact of gender associated with fetal birth weight, head circumference, and birth length for twins; (2) to examine the effect of gender on standardized fetal growth at birth, according to gestational age and birth order; (3) to examine the effect of gender on placenta weight and dimensions. Methodology: This was a populationbased retrospective cohort study of twins (4,368 twins, 2,184 pairs) born in British Columbia, Canada from 2000-2010. We excluded twins with stillbirth, congenital anomalies, and those delivered with cesarean section. We also controlled for confounding factors, including birth order, gestational age, maternal anthropometric measures, maternal smoking habits, and obstetric history. A subsample of this population was analyzed from Children and Women Hospital to obtain chorionicity information. Results: Male-male twins were heavier than male-females and female-female twin pairs $(p=.01)$. Within sex-discordant twin pairs, males were also heavier than females $(p=.01)$. Regression analysis suggested that gender affects birth weight independent of birth order and gestational age. Other newborn anthropometric measures were not found to be dependent on gender. In analyzing a subsample with chorionicity data, birth weight was the only anthropometric measure that was both statistically and clinically affected by sex, even after adjustment for gestational age, chorionicity, birth order, and maternal age. Conclusion: Birth weight was affected by gender while head circumference and birth length were not.
\end{abstract}

Keywords: twin, gender, anthropometric measures

The impact of gender on fetal growth has been studied in both singleton and twin pregnancies (Chase, 1969; Cogswell \& Yip, 1995; Williams et al., 1982). In singleton pregnancies, female infants weigh less than male ones in all gestations (Cogswell \& Yip, 1995; Williams et al., 1982). This finding is conceived as the effect of androgens, produced in male infants, that increase birth weight (Luke et al., 2005). In twin gestations, females who share the uterus with a male (female-male or sex-discordant twin pairs) are found to be heavier than females who share the uterus with another female (sex-concordant pairs; Miller, 2003). It has been hypothesized that fetal exposure of females from sexdiscordant twin pairs to androgen-producing males leads to increase in fetal growth (Miller \& Martin, 1995).

The metabolic action of androgens in males also alters the gestational length, namely the time course in utero (Loos et al., 2001). Males are born earlier than females (James, 2000, 2002). It is not clear what the mechanism behind this phenomenon is. Apart from birth weight and gestational age, the impact of gender on other measures of fetal growth should be taken into consideration, as it is often reported that intrauterine growth of multiple birth neonates shows asymmetrical hypotrophy (Hennequin et al., 1999; Winter et al., 1994). Few studies have examined the divergent head growth and birth length in sex-discordant twins. Ultrasound monitoring of fetal growth shows that males, on average, have $2.0 \mathrm{~mm}$ longer crown-rump length by $8-$ 12 weeks of gestation, $1.4 \mathrm{~mm}$ larger transverse diameter of the head by 16 weeks of gestation, and $4.0 \mathrm{~mm}$ longer birth length than females (Pedersen, 1980). It is hypothesized that gender determines not only the birth weight but also other anthropometric measures (Luke et al., 2005). To test the

RECEIVED 21 March 2016; ACCEPTEd 4 May 2016. First published online 21 July 2016.

ADDRESS FOR CORRESPONDENCE: Shayesteh Jahanfar, PhD, School of Population and Public Health, The University of British Columbia, 2206 East Mall, Vancouver, BC V6T 1Z3, Canada. E-mail: shayesteh.jahanfar@ubc.ca 
hypothesis, we aimed at investigating the role of gender on birth weight, length, and head circumference, while adjusting for important confounding variables. Previous studies failed to adjust for confounding factors, including gestational age, birth order, maternal age, maternal height, prepregnancy weight, maternal weight gain during pregnancy, parity, maternal smoking habits, gestational diabetes, and pregnancy induced hypertension.

\section{Methodology}

We conducted a retrospective, population-based cohort study of twins born between April 1, 2000 and December 2010, using data from Perinatal Services BC's (PSBC) Perinatal Data Registry (PSBC, 2014). The database contains information on approximately $99 \%$ births in the province of British Columbia, Canada. Information in the registry is compiled from standardized forms completed by clinicians. The validity of the data is ensured by quality control measures, including built-in warnings in the data entry software, and periodic checking of the data. Ethics approval for the study was obtained from Ethics Review Board of University of British Columbia and Children's and Women's Hospital, Vancouver (H11-03281).

Data was accessed via Population Data BC's Secure Research Environment (SRE). SRE is a central server accessible only via an encrypted Virtual Private Network through the firewall and use of a Yubikey ${ }^{\circledR}$ for two-factor authentication. It provides researchers with secure storage and backup, centralized location for access and processing of research data, SPSS software, and security standards that meet the Canadian Standards Association's Ten Privacy Principles. These principles protect personal information as per detailed requirements of the BC Freedom of Information and protection of Privacy Act. None of the authors have any competing interests.

Exclusion criteria were as follows: gestational age at delivery less than 20 weeks of gestation, stillbirth of one of the twins, major congenital anomalies, and twins born from cesarean section, as this affects the gestational age as well as birth weight.

The outcomes were inclusive of anthropometric measures of newborns, including birth weight, head circumference, and birth length. Variables that were tested for their role as confounders were as follows: maternal age, maternal anthropometric measures (pre-pregnancy weight, height, body mass index, maternal weight gain during pregnancy), maternal smoking habits (never smoker, former smoker, current smoker), medical problems during pregnancy (gestational diabetes, pregnancy-induced hypertension), obstetric history (history of delivering a baby with congenital anomaly, history of delivery a low birth weight infant), birth order, and gestational age.

Gestational age was calculated based on an algorithm considering last menstrual period (LMP) and LMP con- firmed with ultrasound examination ( $<20$ weeks). When the two estimates were concordant, the LMP-based estimate was used, whereas in cases of discordancy of more than 2 weeks between the estimates, the ultrasound estimate was used. The algorithm was adapted from the Society of Obstetrician and Gynecologists (SOGC) guidelines (Canadian Institute for Health Information, 2007). Standardized fetal growth was categorized as the following: SGA $(<10$ th percentile), AGA (10-89th percentile), and LGA (90th percentile and more), based on twin growth curves derived from a clinical twin population with reliable gender-specific gestational age estimates (Cohen et al., 1997).

The birth weight discordancy was computed as percentage of the larger twin's birth weight, (larger birth weightsmaller birth weight)/larger birth weight $\times 100$.

Twins were classified into three groups according to fetal sex: male-male $(n=1,515)$, female-female $(n=1,407)$, and male-female $(n=1,446)$. The mean and standard deviations $(S D)$ of gestational age, birth weight, head circumference, and birth length for twins were calculated according to sex-discordance. The significance of differences between mean values was tested using Student's $t$ test where the comparison was between two groups and using ANOVA where the comparison was among more than two groups.

\section{Subgroup Analysis}

A subgroup analysis was done for twins who had chorionicity information. Following exclusion of twins with stillbirth, chromosomal anomaly and those who had cesarean section, there were 3,132 subjects remaining in the study, including male-male, 550 pairs; female-female, 520 pairs; and male-female, 496 pairs. Anthropometric measures were estimated for overall differences between these three groups in the current study.

The factors affecting fetal growth were then investigated by stepwise regression analysis. In sequential models, one potential confounding variable was tested at a time. Retaining the most statistically significant variable, remaining variables were entered separately in sequential models, and then the process was repeated until all variables have been tested. A significant level of less than 0.05 was considered as a threshold for keeping a variable in the model. Data analysis was performed using SPPS version 20 (SPSS Inc., Chicago, IL, USA).

\section{Results}

Table 1 contains the mean $\pm S D$ for gestational age, birth weight, head circumference, and birth length analyzed according to sex-concordance. We compared three sex pairing categories of male-male, female-female, and malefemale. Comparing the anthropometric measures of infants, we did not find any significant difference between the three sex pairing groups for gestational age, head circumference, and length. However, we found a statistically 
TABLE 1

Effect of Gender on Fetal Growth in Three Categories of Gender Mix (4,368 Twins, 2,184 Pairs)

\begin{tabular}{|c|c|c|c|c|c|c|c|}
\hline & \multicolumn{3}{|c|}{ Gender mix } & \multicolumn{3}{|c|}{ Student's $t$ test } & \multirow[b]{2}{*}{$p^{\wedge}$} \\
\hline & MM 1,515 pairs & MF 1,446 pairs & FF 1,407 pairs & $\mathrm{MM}$ versus FF & $\mathrm{MM}$ versus $\mathrm{MF}$ & FF versus MF & \\
\hline Gestational age, week & $35.36 \pm 4.43$ & $35.49 \pm 4.26$ & $35.42 \pm 4.11$ & 0.72 & 0.38 & 0.62 & .68 \\
\hline Birth weight, $g$ & $2458 \pm 655$ & $2497 \pm 596$ & $2370 \pm 602$ & 0.01 & 0.01 & 0.01 & .01 \\
\hline Head circumference, $\mathrm{cm}$ & $32.86 \pm 2.38$ & $32.89 \pm 2.31$ & $32.76 \pm 2.45$ & 0.25 & 0.73 & 0.14 & .30 \\
\hline Birth length, $\mathrm{cm}$ & $47.31 \pm 3.96$ & $47.59 \pm 3.84$ & $47.35 \pm 4.13$ & 0.78 & 0.06 & 0.28 & .11 \\
\hline
\end{tabular}

Note: ${ }^{\wedge}$ ANOVA test; $M M=$ male-male; $M F=$ male-female; $F F=$ female-female.

TABLE 2

Effect of Gender on Fetal Growth in Sex-Discordant Twins (4,368 Twins, 2,184 Pairs)

\begin{tabular}{|c|c|c|c|c|c|}
\hline & $\begin{array}{l}\text { Male from MF pairs } \\
n=723\end{array}$ & $\begin{array}{l}\text { Female from MF pairs } \\
n=723\end{array}$ & $\begin{array}{l}\text { Female from FF pairs } \\
n=1407\end{array}$ & $\begin{array}{l}\text { Female versus } \\
\text { male from MF } \\
\text { pairs }\end{array}$ & $\begin{array}{l}\text { Female from MF } \\
\text { pairs versus } \\
\text { female from FF } \\
\text { pairs }\end{array}$ \\
\hline Gestational age, wk. & $35.39 \pm 4.38$ & $35.45 \pm 4.16$ & $35.42 \pm 4.12$ & $0.79^{*}$ & 0.60 \\
\hline Birth weight, $g$ & $2485 \pm 639$ & $2398 \pm 599$ & $2370 \pm 602$ & $0.01^{*}$ & 0.01 \\
\hline Head circumference, $\mathrm{cm}$ & $32.88 \pm 2.31$ & $32.79 \pm 2.46$ & $32.76 \pm 2.48$ & $0.74^{*}$ & 0.39 \\
\hline Birth length, $\mathrm{cm}$ & $47.39 \pm 3.89$ & $47.44 \pm 4.06$ & $47.35 \pm 4.13$ & 0.70 & 0.17 \\
\hline
\end{tabular}

Note: *Kruskal-Wallis test; $\mathrm{MM}=$ male-male; $\mathrm{MF}=$ male-female; $\mathrm{FF}=$ female-female; $w \mathrm{k}$. = week; $\mathrm{g}=\mathrm{gram}$; $\mathrm{cm}=$ centimeter.

significant difference between birth weight of three groups (male-male: $2458 \pm 655 \mathrm{~g}$, male-female: $2497 \pm 596 \mathrm{~g}$, female-female: $2370 \pm 602 \mathrm{~g} ; p=.01)$. Discordant twin pairs (male-female) were heavier than the two other groups, while female-female pairs were the lightest. Malefemale twin pairs were $127 \mathrm{~g}$ heavier than the femalefemale group $(p=.01)$ and only $39 \mathrm{~g}$ heavier than the malemale group $(p=.01)$. Female-female pairs were $88 \mathrm{~g}$ lighter than male-male pairs $(p=.01)$.

We then investigated the difference between individual males and females within male-female twin pairs (Table 2). Differences between groups in terms of head circumference and birth length were insignificant. Among sex discordant twin pairs, males were $87.0 \mathrm{~g}$ heavier than their female counterparts. Females from sex-discordant twins (malefemale) were $28.0 \mathrm{~g}$ heavier than females of sex-concordant twins (female-female; $p=.01$ ).

Table 3 contains the overall mean birth weight, birth length, and head circumference analyzed according to fetal and maternal characteristics. Prior histories of congenital anomaly and low birth weight were significantly associated with measures such as head circumference and birth length but not with birth weight, while birth order was associated with birth weight. Maternal diseases during pregnancy (gestational diabetes, hypertension), anthropometric measures of mother (weight, height, BMI), and weight gain during pregnancy were not associated with either of the dependent variables. All the outcome variables, however, were associated with gestational age and gender.

The results of stepwise linear regression analysis on birth weight, head circumference, and birth length are presented in Table 4. Although sex entered the birth weight model as the main independent variable and was significantly associated with birth weight, the contribution of gestational age was strongest in the module. Birth order was also associated with birth weight. Considering male as a reference category, female counterparts were $95.0 \mathrm{~g}$ lighter than males after adjusting for baby order and gestational age.

Gender was not associated with head circumference and birth length, while histories of delivering a baby with congenital anomaly and/or low birth weight were. Maternal characteristics, including maternal age, parity, smoking habit, diseases during pregnancy, and anthropometric measures, did not reach the significance level $(p=.05)$ for entry into the models. Data are not shown.

To investigate the impact of chorionicity on anthropometric measures, a subsample of data was analyzed (Table 5). All anthropometric measures were found to be significantly different in sex-pairing groups. Similar to the analysis of the whole dataset, a subgroup analysis of twin data, with chorionicity information, showed that malefemale twins were heavier in weight and taller in height, followed by male-male twin pairs; and finally, female-female twins were the lightest and shortest. Stratified data by chorionicity showed statistically significant differences in all anthropometric measures for DC twins. MC twins had different birth weight and birth length $(p=.01)$.

Gestational age was found to be different among three groups (ANOVA, $p=.02$ ) suggesting that this variable should be adjusted for in regression modeling. We made such an adjustment, which led to the disappearance of impact of gender on all anthropometric measures except birth weight. Considering male as a reference category, female counterparts were $79 \mathrm{~g}$ lighter than males (-78.72; 
TABLE 3

Socio-Demographic and Clinical Characteristics of Mothers and Twins (4,368 Twins, 2,184 Pairs)

\begin{tabular}{|c|c|c|c|}
\hline & Birth weight & Birth length & Head circumference \\
\hline \multicolumn{4}{|l|}{ Sex } \\
\hline Male & $2485 \pm 639^{*}$ & $47.39 \pm 3.89^{*}$ & $32.88 \pm 2.31 *$ \\
\hline Female & $2398 \pm 599$ & $47.44 \pm 4.06$ & $32.79 \pm 2.47$ \\
\hline \multicolumn{4}{|c|}{ Gestational age (weeks) } \\
\hline$<32$ & $1913 \pm 843^{*}$ & $44.03 \pm 6.47^{*}$ & $44.03 \pm 6.47^{*}$ \\
\hline $32-36$ & $2356 \pm 431$ & $46.74 \pm 3.05$ & $46.74 \pm 3.05$ \\
\hline$\geq 37$ & $2728 \pm 444$ & $48.79 \pm 2.94$ & $48.79 \pm 2.94$ \\
\hline \multicolumn{4}{|c|}{ Maternal smoking habit } \\
\hline Current smoked & $2467 \pm 612$ & $47.48 \pm 3.87$ & $32.89 \pm 2.33$ \\
\hline Former smoker & $2479 \pm 555$ & $47.39 \pm 3.99$ & $32.69 \pm 2.37$ \\
\hline Never smoker & $2437 \pm 543$ & $47.34 \pm 3.74$ & $32.72 \pm 2.56$ \\
\hline \multicolumn{4}{|l|}{ Birth order } \\
\hline First-born & $2492 \pm 591^{*}$ & $47.35 \pm 4.07$ & $32.85 \pm 2.42$ \\
\hline Second-born & $2454 \pm 591$ & $47.48 \pm 3.87$ & $32.83 \pm 2.35$ \\
\hline \multicolumn{4}{|l|}{ Parity } \\
\hline Primiparous & $2493 \pm 573$ & $47.48 \pm 3.82$ & $32.89 \pm 2.28$ \\
\hline Multiparous & $2453 \pm 608$ & $47.34 \pm 4.13$ & $32.78 \pm 2.49$ \\
\hline \multicolumn{4}{|l|}{ Maternal age (year) } \\
\hline$\leq 24$ & $2450 \pm 615$ & $47.40 \pm 4.17$ & $32.75 \pm 2.58$ \\
\hline $25-34$ & $2476 \pm 580$ & $47.45 \pm 3.84$ & $32.88 \pm 2.25$ \\
\hline$\geq 35$ & $2477 \pm 602$ & $47.34 \pm 4.14$ & $32.79 \pm 2.54$ \\
\hline \multicolumn{4}{|l|}{ Maternal weight $(\mathrm{kg})$} \\
\hline$<70$ & $2480 \pm 582$ & $47.40 \pm 3.91$ & $32.84 \pm 2.34$ \\
\hline$\geq 70$ & $2482 \pm 591$ & $47.56 \pm 4.02$ & $32.93 \pm 2.45$ \\
\hline \multicolumn{4}{|c|}{ Maternal height (cm) } \\
\hline$\leq 160$ & $2504 \pm 543$ & $47.67 \pm 3.36$ & $47.67 \pm 3.36$ \\
\hline$>160$ & $2472 \pm 604$ & $47.37 \pm 4.16$ & $47.37 \pm 4.16$ \\
\hline \multicolumn{4}{|c|}{ Maternal BMI $\left(\mathrm{kg} / \mathrm{m}^{2}\right)$} \\
\hline$\leq 19$ & $2464 \pm 606$ & $47.59 \pm 3.62$ & $32.88 \pm 2.26$ \\
\hline$\overline{20}-24$ & $2491 \pm 571$ & $47.44 \pm 3.93$ & $32.85 \pm 2.31$ \\
\hline$\geq 25$ & $2481 \pm 590$ & $47.48 \pm 3.99$ & $32.88 \pm 2.46$ \\
\hline \multicolumn{4}{|c|}{ Pregnancy weight gain $(\mathrm{kg})$} \\
\hline$<6$ & $2543 \pm 530$ & $47.93 \pm 3.94$ & $33.43 \pm 2.66^{*}$ \\
\hline $6-12$ & $2484 \pm 577$ & $47.49 \pm 3.89$ & $32.87 \pm 2.36$ \\
\hline$>12$ & $2476 \pm 568$ & $47.57 \pm 3.62$ & $32.98 \pm 2.01$ \\
\hline \multicolumn{4}{|l|}{ Maternal diabetes } \\
\hline No & $2473 \pm 591$ & $47.42 \pm 3.98$ & $32.83 \pm 2.39$ \\
\hline Yes & $2475 \pm 592$ & $47.31 \pm 3.96$ & $32.91 \pm 2.42$ \\
\hline \multicolumn{4}{|c|}{ Maternal hypertension } \\
\hline Diseases & $2477 \pm 580$ & $47.40 \pm 3.99$ & $32.84 \pm 2.37$ \\
\hline No & $2450 \pm 654$ & $47.40 \pm 3.98$ & $32.82 \pm 2.47$ \\
\hline Yes & & & \\
\hline \multicolumn{4}{|c|}{ Prior gestation with LBW } \\
\hline No & $2475 \pm 593$ & $47.42 \pm 3.99^{*}$ & $32.85 \pm 2.39^{*}$ \\
\hline Yes & $2343 \pm 494$ & $47.14 \pm 3.17$ & $32.44 \pm 2.10$ \\
\hline \multicolumn{4}{|l|}{$\begin{array}{l}\text { Prior gestation with } \\
\text { congenital anomaly }\end{array}$} \\
\hline No & $2473 \pm 591$ & $47.40 \pm 3.99^{*}$ & $32.83 \pm 2.40^{*}$ \\
\hline Yes & $2507 \pm 630$ & $48.53 \pm 2.60$ & $33.79 \pm 1.41$ \\
\hline
\end{tabular}

Note: ${ }^{*} p=.05$ or lower; $\mathrm{BMI}=$ Body Mass Index, there were missing data for maternal weight, height, BMI, and weight gain; nulliparous women did not have information on prior pregnancy history. These were excluded.

TABLE 4

Multiple Linear Regression Analysis of Factors Associated With Birth Weight, Head Circumference, and Birth Length (4,368 Twins, 2,184 Pairs)

\begin{tabular}{llllll}
\hline Dependent variable & Independent variable & Beta & $p$ value & $F$ & Adjusted $r^{2}$ \\
\hline Birth weight & Sex (Male = Ref) & -95.129 & .001 & 478.369 & 0.247 \\
& Baby order & -31.309 & .001 & & \\
Head circumference & Gestational age & 409.411 & .001 & & \\
Birth length & Prior congenital anomaly & -0.958 & .006 & 7.497 & 0.002 \\
& Prior congenital anomaly & -1.133 & .05 & 3.773 & 0.001 \\
\hline
\end{tabular}


TABLE 5

Effect of Gender on Fetal Growth in Sex-Discordant Twins in Subsample Data with Chorionicity Information $(n=3,182)$

\begin{tabular}{lcccccc}
\hline & MM 550 pairs (35.1\%) & MF 496 pairs (31.7\%) & FF 520 pairs (33.2\%) & Overall & Monochorionic & Dichorionic \\
\hline Gestational age & $34.53 \pm 3.54$ & $34.26 \pm 3.74$ & $34.08 \pm 3.73$ & 0.02 & 0.01 & 0.20 \\
Birth weight & $2258.14 \pm 719$ & $2314 \pm 675$ & $2173.89 \pm 683$ & 0.01 & $0.11^{*}$ & 0.01 \\
Head circumference & $32.44 \pm 3.06$ & $32.30 \pm 3.10$ & $31.75 \pm 3.03$ & 0.01 & $0.01^{*}$ & $0.01^{*}$ \\
Birth length & $46.13 \pm 4.93$ & $47.12 \pm 4.69$ & $45.49 \pm 4.88$ & 0.01 & 0.18 & 0.01 \\
BWD & $13.36 \pm 13.38$ & $12.84 \pm 10.37$ & $12.17 \pm 11.83$ & $0.01^{*}$ & 0.13 & $0.01^{*}$ \\
\hline
\end{tabular}

Note: *Kruskal-Wallis Test; MM = Male-Male; MF = male-female; FF = female-female; BWD = birth weight discordance.

TABLE 6

A Comparison of Birth Weight of Males Versus Females in the Literature

\begin{tabular}{llll}
\hline Study, year & Sample & $\begin{array}{l}\text { Males were heavier } \\
\text { than female }\end{array}$ & Limitation \\
\hline Orlebeke et al., 1993 & Dizygotic twin pairs & NS & Did not control for birth order \\
Treloar \& Whitfield, 2002 & Dizygotic twin pairs & Yes & Used zygosity rather than chorionicity \\
Glinianaia et al., 1998 & Dizygotic sex concordant and sex discordant twin pairs & Yes & Controlled for gestational age \\
Blumrosen et al., 2002 & Sex concordant and sex discordant & Yes & Did not control for gestational age \\
\hline
\end{tabular}

Note: $\mathrm{NS}=$ non-significant result.

95\% CI -103.71 to -53.73) after adjusting for maternal age, chorionicity, gestational age, birth order, which was a similar pattern observed in the analysis of whole data. Risk ratios for head circumference $(-0.57 ; 95 \%$ CI -0.69 to -0.44$)$, birth length $(-0.43 ; 95 \%$ CI-0.63 to -0.23$)$ and birth weight discordance $(-0.88 ; 95 \%$ CI -1.70 to -0.06$)$ were statistically significantly but clinically negligible.

\section{Discussion}

Our population-based retrospective study examined a large cohort of twins $(n=4,368)$ born in British Columbia, Canada. We were able to adjust for maternal characteristics (age, anthropometric measures, weight gain during pregnancy, smoking habits, and diseases during pregnancy) as well as birth order, gestational age, and obstetric history. Our findings suggest that within concordant twin pairs, male-male pairs were heavier than female-female pairs. Additionally, within sex-discordant pairs, males were heavier than females. Moreover, females who shared a uterus with a male were heavier than females who did not. These findings suggest that male gender increases growth of co-twin.

Male-male twin pairs were lighter than male-female twin pairs. This could relate to slightly shorter gestational age of male-male pairs compared with that of the malefemale pairs, although, this difference was not statistically significant.

Regression analysis and comparing standardized fetal growth verified the impact of gender on birth weight but not on head circumference and birth length.

The male hormone may be responsible for stimulating growth both in the male and in his female co-twin, resulting in the female co-twin of sex-discordant pair growing more than sex-concordant female pairs. This finding confirms that male gender can have a positive impact on the growth of co-twin. Similar to our finding, Blickstein and Weissman (1990) found that within sex-discordant twin pairs, males were, in $31 \%$ of all cases, more than $15 \%$ heavier than females. It is debatable whether large birth weight difference in sex-discordant pairs can be explained by confounding factors (e.g., gestational age, birth order, zygosity, chorionicity) or whether a specific effect of fetal growth is present in sex-discordant pairs. Loos et al. (2001) reported similar weight between females from sex-discordant pairs compared with females of sex-concordant pairs, but males from sex-discordant pairs weighed $78.0 \mathrm{~g}$ more than males from sex-concordant pairs ( $p=.001$; Loos et al., 2001). They suggested that the higher weight of a male co-twin of a sexdiscordant pair may be the result of longer gestations in pregnancies carrying female fetuses. Our results showed an association between gender and gestational age (Tables 3 and 4). However, after controlling for gestational age, we were still able to show the impact of gender on birth weight. The same pattern of association was observed when analyzing a subgroup with chorionicity data (Table 5).

Table 6 summarizes studies that look at the birth weight of males compared with females. Some of these studies did not control for important confounding variables such as birth order and gestational age. Three of such studies (Orlebeke et al., 1993; Treloar \& Whitfield, 2002; and Glinianaia et al., 1998) analyzed dizygotic twin pairs only while Blumrosen et al.(2002) studied sex-concordant and discordant twins, similar to our study. The discrepancy between studies can be partly explained by not adjusting for suitable confounding variables or inappropriate selection of the cases. Our study eliminated twins with stillbirth and congenital anomalies. Twins born through cesarean section 
were also excluded from our study population as cesarean section can shorten gestation somewhat, leading to lower birth weight or incomplete fetal growth. We also controlled for confounding factors such as gestational age, birth order and chorionicity. We were not able to control for zygosity, although previous studies showed that the effect of gender on fetal growth is independent of this variable (Glinianaia et al., 1998; Treloar \& Whitfield, 2002).

Our study was unique in terms of providing information on the effect of gender on head circumference and birth length among sex-discordant twins, for which we did not find any statistically significant association (Table 2). Similarly, no association was found for head circumference or birth length with gender when comparing sex-discordant pairs with sex-concordant twins (Table 1) or when chorionicity was controlled in a smaller population (Table 6). This could be due to the impact of genetic factors, which are independent of gender, compared with environmental factors. High heritability of head circumference and height is reported in the literature. A study of 88 twin pairs, recruited from university hospitals in United States, showed that genetic play a greater role on head circumference rather than gender with or without controlling for chorionicity and zygosity (Mukherjee et al., 2009). Heritability of head size is estimated about $90 \%$ in young infants in twin-sib families of Australian and Dutch population (Smith et al., 2010).

Gender was not associated with birth length in our study. Few results have been reported on infant height and its association with gender. Our finding is consistent with the findings of Jaya et al. (1995). They studied a small set of twin pairs (209 pairs) and found no significant difference in the body length of twin babies in relation to sex. Wälli et al. (1980) compared 104 sets of twin pair's birth lengths with that of singleton gestation without separation according to gender for the twins. Combined twins' lengths averaged about $1 \mathrm{~cm}$ less than singleton girls, or $2 \mathrm{~cm}$ less than singleton boys at 35 weeks of gestation. Yokoyama et al. (2005) studied 370 mothers and their 1,109 triplet children in Japan and found that male neonates had a longer birth length than female neonates.

In conclusion, we have found a tendency for male prenatal growth to influence the co-twin female. Birth weight was the only measure that was affected by gender. Head circumference and birth length are probably affected by non$\mathrm{X}$-linked genes rather than the environmental factors such as intrauterine hormone. Future studies are needed to measure hormones in newborn females who shared uterus with a male twin.

\section{Acknowledgments}

Many thanks to Dr Eugenia Oviedo-Joekes, Dr Patricia Spittal, and Dr Martin Schechter, the members of thesis research committee for the $\mathrm{PhD}$ program. This study was supported by a grant from the Canadian Institutes of Health Research (MAH-115445).

\section{Disclaimer Requirement}

All inferences, opinions, and conclusions drawn in this publication are those of the authors, and do not reflect the opinions or policies of the Data Steward(s).

\section{References}

Blickstein, I., \& Weissman, A. (1990). Birth weight discordancy in male-first and female-first pairs of unlike-sexed twins. American Journal of Obstetrics and Gynecology, 162, 661-663.

Blumrosen, E., Goldman, R. D., \& Blickstein, I. (2002). Growth discordance and the effect of a male twin on birth weight of its female co-twin: A population-based study. Journal of Perinatal Medicine, 30, 510-513.

Canadian Institute for Health Information. (2007). Canadian coding standards for ICD-10-CA and CCI for 2008. Ottawa: Author. Retrieved from www.cihi.ca

Chase, H. C. (1969). Infant mortality and weight at birth: 1960 United States birth cohort. American Journal of Public Health and the Nation's Health, 59, 1618-1628.

Cogswell, M. E., \& Yip, R. (1995). The influence of fetal and maternal factors on the distribution of birthweight. Seminars in Perinatology, 19, 222-240.

Cohen, S. B., Dulitzky, M., Lipitz, S., Mashiach, S., \& Schiff, E. (1997). New birth weight nomograms for twin gestation on the basis of accurate gestational age. American Journal of Obstetrics and Gynecology, 177, 1101-1104.

Glinianaia, S. V, Magnus, P., Harris, J. R., \& Tambs, K. (1998). Is there a consequence for fetal growth of having an unlikesexed cohabitant in utero?. International Journal of Epidemiology, 27, 657-659.

Hennequin, Y., Rorive, S., Vermeylen, D., \& Pardou, A. (1999). [Twins: Interpretation of height-weight curves at birth]. Revue Médicale de Bruxelles, 20, 81-85.

James, W. H. (2000). Why are boys more likely to be preterm than girls? Plus other related conundrums in human reproduction. Human Reproduction, 15, 2108-2111.

James, W. H. (2002). Gestation and birthweight in dizygotic twins. Lancet, 359, 171-172.

Jaya, D. S., Kumar, N. S., \& Bai, L. S. (1995). A study on the health status of twin babies. Indian Journal of Pediatrics, 62, 357-361.

Loos, R. J., Derom, C., Eeckels, R., Derom, R., \& Vlietinck, R. (2001). Length of gestation and birthweight in dizygotic twins. Lancet, 358, 560-561.

Luke, B., Hediger, M., Min, S.-J., Brown, M. B., Misiunas, R. B., Gonzalez-Quintero, V. H., ... Macones, G. A. (2005). Gender mix in twins and fetal growth, length of gestation and adult cancer risk. Paediatric and Perinatal Epidemiology, 19(Suppl. 1), 41-47.

Miller, D. A. (2003). Project 27/28: Implications for midwives. The Practising Midwife, 6, 14-17.

Miller, E. M., \& Martin, N. (1995). Analysis of the effect of hormones on opposite-sex twin attitudes. Acta Geneticae Medicae et Gemellologiae, 44, 41-52. 
Mukherjee, N., Kang, C., Wolfe, H. M., Hertzberg, B. S., Smith, J. K., Lin, W., ... Gilmore, , J. H. Gilmore (2009). Discordance of prenatal and neonatal brain development in twins. Early Human Development, 85, 171-175.

Orlebeke, J. F., van Baal, G. C., Boomsma, D. I., \& Neeleman, D. (1993). Birth weight in opposite sex twins as compared to same sex dizygotic twins. European Journal of Obstetrics, Gynecology, and Reproductive Biology, 50, 95-98.

Pedersen, J. F. (1980). Ultrasound evidence of sexual difference in fetal size in first trimester. British Medical Journal, 281, 1253.

Perinatal Services British Columbia. (2014). British columbia perinatal data registry manual. Vancouver, Canada: Author.

Smith, N. A., Lyons, J. G., \& McElrath, T. F. (2010). Protein: Creatinine ratio in uncomplicated twin pregnancy. American Journal of Obstetrics and Gynecology, 203, 381.e1-4.
Treloar, S., \& Whitfield, J. (2002). Birthweights in same-sex and opposite-sex twin pregnancies. Twin Research, 5, 310.

Wälli, R., Stettler, T., Largo, R. H., Fanconi, A., \& Prader, A. (1980). Weight, length and head circumference of the newborn infant and their relationship to maternal and infant factors. Standards for intrauterine growth. Helvetica Paediatrica Acta, 35, 397-418.

Williams, R. L., Creasy, R. K., Cunningham, G. C., Hawes, W. E., Norris, F. D., \& Tashiro, M. (1982). Fetal growth and perinatal viability in California. Obstetrics and Gynecology, 59, 624-632.

Winter, A., Juez, G., Lucero, E., \& Donoso, E. (1994). Intrauterine growth in full-term twins without risk factors. Revista Chilena de Obstetricia y Ginecología, 59, 123-127.

Yokoyama, Y., Sugimoto, M., \& Ooki, S. (2005). Analysis of factors affecting birthweight, birth length and head circumference: Study of Japanese triplets. Twin Research and Human Genetics, 8, 657-663. 